\title{
The effectiveness of peer and community health worker-led self-management support programs for improving diabetes health-related outcomes in adults in low- and-middle-income countries: a systematic review
}

Mahmoud Werfalli, ${ }^{1,2}$, Peter J. Raubenheimer ${ }^{2}$, Mark Engel ${ }^{2}$, Alfred Musekiwa ${ }^{3}$, Kirsten Bobrow ${ }^{1,2}$, Nasheeta Peer $^{2,3}$, Cecilia Hoegfeldt ${ }^{4}$, Sebastiana Kalula ${ }^{2,5}$, Andre Pascal Kengne ${ }^{2,6}$ and Naomi S. Levitt ${ }^{1,27^{*}}$ (D)

\begin{abstract}
Objective: Community-based peer and community health worker-led diabetes self-management programs (COMPDSMP) can benefit diabetes care, but the supporting evidence has been inadequately assessed. This systematic review explores the nature of COMP-DSMP in low- and middle-income countries' (LMIC) primary care settings and evaluates implementation strategies and diabetes-related health outcomes.
\end{abstract}

Methods: We searched the Cochrane Library, PubMed-MEDLINE, SCOPUS, CINAHL PsycINFO Database, International Clinical Trials Registry Platform, Clinicaltrials.gov, Pan African Clinical Trials Registry (PACTR), and HINARI (Health InterNetwork Access to Research Initiative) for studies that evaluated a COMP-DSMP in adults with either type 1 or type 2 diabetes in World Bank-defined LMIC from January 2000 to December 2019. Randomised and nonrandomised controlled trials with at least 3 months follow-up and reporting on a behavioural, a primary psychological, and/or a clinical outcome were included. Implementation strategies were analysed using the standardised implementation framework by Proctor et al. Heterogeneity in study designs, outcomes, the scale of measurements, and measurement times precluded meta-analysis; thus, a narrative description of studies is provided.

Results: Of the 702 records identified, eleven studies with 6090 participants were included. COMP-DSMPs were inconsistently associated with improvements in clinical, behavioural, and psychological outcomes. Many of the included studies were evaluated as being of low quality, most had a substantial risk of bias, and there was a significant heterogeneity of the intervention characteristics (for example, peer definition, selection, recruitment, training and type, dose, and duration of delivered intervention), such that generalisation was not possible.

\footnotetext{
* Correspondence: Naomi.Levitt@uct.ac.za

'Chronic Disease Initiative for Africa, Cape Town, Western Cape, South Africa

${ }^{2}$ Department of Medicine, Faculty of Health Science, University of Cape

Town, Observatory, Cape Town, Western Cape 7935, South Africa

Full list of author information is available at the end of the article
}

(c) The Author(s). 2020 Open Access This article is licensed under a Creative Commons Attribution 4.0 International License, which permits use, sharing, adaptation, distribution and reproduction in any medium or format, as long as you give appropriate credit to the original author(s) and the source, provide a link to the Creative Commons licence, and indicate if changes were made. The images or other third party material in this article are included in the article's Creative Commons licence, unless indicated otherwise in a credit line to the material. If material is not included in the article's Creative Commons licence and your intended use is not permitted by statutory regulation or exceeds the permitted use, you will need to obtain permission directly from the copyright holder. To view a copy of this licence, visit http://creativecommons.org/licenses/by/4.0/. The Creative Commons Public Domain Dedication waiver (http://creativecommons.org/publicdomain/zero/1.0/) applies to the data made available in this article, unless otherwise stated in a credit line to the data. 
(Continued from previous page)

Conclusions: The level of evidence of this systematic review was considered low according to the GRADE criteria. The existing evidence however does show some improvements in outcomes. We recommend ongoing, but welldesigned studies using a framework such as the MRC framework for the development and evaluation of complex interventions to inform the evidence base on the contribution of COMP-DSMP in LMIC.

\section{Introduction}

Over the past decade, diabetes prevalence has risen faster in low- and middle-income countries (LMIC) than in high-income countries (HIC) [1]. Currently, about $80 \%$ of people with diabetes worldwide live in LMIC, and projections suggest that some of these countries will experience more than a twofold increase in the number of people affected over the next 20 years [1]. People living with diabetes need not only medical treatment from their health care providers; equally important is selfmanagement and sustaining complex self-care behaviours. These behaviours (under the umbrella of "selfmanagement") include following complicated medication regimens and often embarking on significant lifestyle changes in diet and exercise programs, monitoring and responding to symptoms, and coping effectively with stress [2-4].

Evaluation of diabetes self-management programs has shown improved health outcomes and reduced utilisation of health services [5-7]. However, without continuous support, many adults will not succeed in managing their condition well, leading to worse health outcomes, including expensive hospitalisations and avoidable complications [8]. It is critical for health care providers and the settings where they work to have the resources and a systematic referral process to ensure that patients with diabetes consistently receive both diabetes selfmanagement education (DSME) and diabetes selfmanagement support (DSMS). DSME is defined as the ongoing procedure of facilitating the knowledge, skill, and ability necessary for diabetes self-care, while DSMS is defined as activities assisting the diabetic patient in implementing and sustaining the behaviours needed to manage his/her condition on an ongoing basis beyond or outside of formal self-management training. The type of support provided can be behavioural, educational, psychosocial, or clinical [9]. The initial DSME is typically provided by a healthcare professional, whereas ongoing support can be provided by personnel without a formal health tertiary education [9]. However, health resources, infrastructure, and well-equipped health staff are often limited in LMIC which complicate the delivery and sustainability of DSME and DSMS [10].

A potential solution for delivering diabetes selfmanagement support could be task-shifting. This is the process whereby tasks are moved, where appropriate, to less specialised health workers and is thus expected to reduce health care expenses while improving health care coverage [11]. Lay health workers from the community such as 'patient-peers' or community health workers (CHW) are ideally suited for such task-shifting since existing research suggests that such programs are an effective and relatively inexpensive means to help patients manage chronic conditions [12, 13]. Furthermore, these programs have been recommended by the World Health Organization review committee on peer support in diabetes as a resourceful way for diabetes management [14].

Existing COMP-DSMPs involve two types of closely related lay health care workers: 'patient-peers' (here called 'peers') and community health workers (CHW). For the purpose of this review, Dennis's [15] comprehensive definition of peer support, as used in a recent Cochrane review [16], is employed. Dennis defines peer support as 'provision of emotional, appraisal and informational assistance by a created social network member who possesses experiential knowledge of a specific behaviour or stressor and similar characteristics as the target population, to address a health-related issue of a potentially or stressed focal person' [15]. To possess this experiential knowledge, peers must be affected by the same condition as the patient population they serve. In the context of diabetes, peers often have diabetes themselves or have a family member with diabetes. Their support can help metabolic control by sharing, discussing, identifying, and facilitating behaviours, which can improve diabetes self-management and overcome obstacles to care and self-care [17].

CHWs constitute another form of lay health workers based in the local community. WHO defines CHWs as health workers without a tertiary education health certificate, who are members of the communities where they work, and are supported by the health system, although not necessarily part of its organisation [18]. In contrast to peers, CHWs do not necessarily have the experiential knowledge of being a patient. Yet, similar to peers, CHWs speak the language and share culture and community with the patients with whom they work. Like peer support, CHW support varies widely across different contexts and may include both self-management support and direct patient care [19, 20]. Furthermore, both CHW and peer-support interventions (here collectively referred to as COMP-DSMPs) differ in the extent 
and type of formal training that peers/CHWs receive, in whether peers/CHW are paid members of a healthcare team or volunteers, in the type and extent of time commitment required of the peers/CHW, and in the principal method of peer support (for example, face-to-face contact versus telephone contact) [21].

A considerable body of evidence from well-designed RCTs, mainly in HIC, demonstrates improved clinical and behavioural outcomes such as glycaemic control in diabetes populations receiving peer/CHWs support [22-31]. This is further supported by several systematic reviews. A systematic review conducted by Zhang et al. suggested that home-visit-intervention and curriculum-combined-reinforcement-intervention performed by peers had a better effect on improving glycaemic control compared to conventional care [32]. Furthermore, a systematic review by Norris et al. reported positive changes in lifestyle and self-care in some studies of $\mathrm{CHW}$-led interventions for diabetes self-management. Although limited data on economic outcomes is available, several studies demonstrated a reduction in health care expenses as a result of the CHW-led intervention [33].

At present, there are no systematic reviews of peer/ CHW support programs for diabetes focusing on LMICs. Furthermore, most systematic reviews to date have not applied a standardised framework for analysing and evaluating the implementation strategies across studies. Systematic categorisation and assessment of implementation outcomes are critical for assessing whether an implementation strategy has been applied successfully since an intervention will not be successful unless both the implementation of the strategy in a given context and the components of the strategy itself are effective [34]. In the case of failure, it is essential to know if this was due to the intervention being ineffective in the new setting (intervention failure), or if an intervention was deployed incorrectly (implementation failure) [35]. To bridge this gap in the existing literature, this systematic review aims to employ a standardised taxonomy for analysing and evaluating COMP-DSMPs implementation strategies in LMIC for diabetes self-management. We strive to answer the following questions: What are the effects of COMP-DSMPs on the clinical and behavioural outcomes of adults with diabetes, and how consistent are those effects across existing studies? What were the program designs used and how were the implementation outcomes assessed?

\section{Methods}

A full study protocol was developed and published in a peer-reviewed journal [36]. This systematic review has been modified from the protocol. Firstly, a meta-analysis was precluded by the quality of the included studies.
Secondly, the research question addressing 'how COMDSMP can help improving quality of diabetes care' has been modified to addressing 'the program designs used, and the implementation outcomes assessed' since there was insufficient information on the quality of care in the included studies. Thirdly, we have added the Risk of Bias in Nonrandomized Studies of Interventions (ROBINS-I) tool for non-randomised studies [37]. Finally, implementation taxonomy frameworks by Proctor et al. have been adopted for the analysis and evaluation of the implementation strategies. This review follows the Preferred Reporting Items for Systematic Reviews and MetaAnalyses (PRISMA) [38] and is registered with the International Prospective Register of Systematic Reviews [registration number CRD42014007531].

\section{Search strategy}

We searched the Cochrane Library, MEDLINE via PubMed, SCOPUS, CINAHL, PsycINFO, and Web of Science databases for studies published between 1 January 2000 and 31 December 2019, which evaluated COMP-DSMPs in adults with diabetes in LMIC. Drawing on a combination of free-text search terms, Medical Subject Headings, and database-specific subject headings, we developed a sensitive search strategy for multiple electronic databases (Additional file 1), combining synonyms for 'diabetes', 'peer support', 'community health worker', 'intervention', and 'LMIC'.

Other database resources such as Google Scholar, WHO, Peer for Progress, International Clinical Trials Registry Platform, Clinicaltrials.gov, Pan African Clinical Trials Registry (PACTR), and HINARI (Health InterNetwork Access to Research Initiative) for LMIC were searched. We similarly explored the reference lists of key articles and journals.

\section{Selection of studies}

Titles and/or abstracts of studies were identified using the search strategy, and those from additional sources were screened independently by two reviewers (MW, PR). They individually assessed the eligibility of the articles first based on the title and abstract and later on full text. Any disagreement between the two reviewers was resolved through discussion with a third author (NSL) on the study team.

\section{Inclusion criteria}

- Types of studies: Studies that measured the effects of COMP-DSMPs in randomised controlled trials (RCTs), non-randomised controlled trials, and quasi-randomised controlled trials were included. The quasi-randomised controlled trials included controlled studies with a comparison group and 
uncontrolled studies with 'before and after' study designs. We included both controlled and noncontrolled before and after studies because they are accepted research designs for improvement strategies and are widely used, especially so in LMIC where the resources are not available to conduct RCTs [35].

- Types of participants/population: Only studies from LMIC based on the World Bank classification of country income groups were included [39]. Study participants had to be $\geq 18$ years of age and have either type 1 or type 2 diabetes, but not gestational diabetes nor diabetes due to other causes. We included type 1 and type 2 diabetes because several studies from LMIC do not differentiate between these two diagnoses.

- Types of interventions: Studies that reported contact with an individual or a group of peers (paid or voluntary) offering COMP-DSMP with a minimum follow-up period of 3 months were included. Peers could be CHW, peer leader, lay health advisor, lay health educators, or peer coaches. Peer support that was exclusively telephone- and web-based was excluded. Interventions led or facilitated by a professional (or non-peer) were included, providing that the focus of the intervention was to provide peer-topeer interaction. Studies in which peer support was part of a multicomponent/complex intervention, where the effects of the peer support element could not be isolated, were excluded.

- Types of control/comparator groups: Studies in which the control/comparator group received usual care or professional health worker-led diabetes selfmanagement support (and not peer support) with a follow-up period of 3 months or more were included.

- Types of outcomes: Studies that reported at least one of the following outcomes were included. Behavioural-such as physical activity/fitness, glucose monitoring, adherence to medication, improved nutrition, and self-care. Psychological-such as self-efficacy, knowledge, attitudes, quality of life, confidence, self-esteem, well-being, vitality, social functioning, and coping, as assessed by validated measures. Clinical-such as fasting and random blood sugar levels, glycated haemoglobin (HbA1c), cholesterol, blood pressure, body mass index (BMI), symptoms of hypoglycaemia and hyperglycaemia, and hospitalisations or clinical visits.

- Language: Restricted to English

- Time restriction: We decided to restrict the search to the period following the changes to the diabetes diagnostic criteria in 1999 based on the WHO Expert Committee on Diagnosis and Classification of
Diabetes. Thus, all studies from 1 January 2000 to 31 December 2019 were eligible if the other inclusion criteria were met.

\section{Assessment of risk of bias of studies}

Four reviewers (MW, PR, NP, and KB) independently evaluated and reported on the risk of bias as described in the Cochrane Handbook for Systematic Reviews of Interventions according to the criteria and associated categorisations contained therein for randomised trials and using the Risk of Bias in Nonrandomized Studies of Interventions (ROBINS-I) tool for non-randomised studies $[37,40]$. A consensus was reached after discussion and consultation with another reviewer (ME).

The quality of evidence for the outcomes was assessed by the Grading of Recommendations Assessment, Development and Evaluation (GRADE) criteria of risk of bias, inconsistency, indirectness, imprecision, and study limitation. The quality assessment was categorized as high, moderate, low, or very low.

\section{Data extraction and synthesis}

The following data were extracted independently by three reviewers (MW, PR, and NP): author, year of publication, geographic region, study design, description of the intervention (including process, cost of programme, cost-effectiveness if available, context of intervention (i.e. primary health facility), details about group leader (demographics, training, professional status, etc.), details about participants (including number of each group, baseline health information, demographic characteristics), length of intervention and follow-up, definition of peer used, and health outcomes. The data abstraction forms based on the Cochrane Consumers and Communication Review Group's Data Extraction Template for Cochrane Reviews were modified to fit this review (Additional file 2). A consensus was reached by discussion and consultation with other reviewers (ME, NSL) where necessary.

\section{Taxonomy for analysing implementation strategies}

The taxonomy used to investigate and evaluate the implementation strategy of each study is based on previously published conceptual frameworks by Proctor et al. [41, 42]. Proctor et al. [41] propose guidelines for naming, defining, and operationalising implementation strategies in terms of seven dimensions: actor, the action, action targets, temporality, dose, implementation outcomes addressed, and theoretical justification. For this review, we categorised and analysed the included studies by applying six of the proposed dimensions (Table 2), while 'implementation outcomes addressed' are separately analysed by the taxonomy proposed by Proctor et al. [42] (Table 3). Although the conceptual framework 
is intended for researchers planning implementation strategies, it allows for systematic investigation, evaluation, and comparison of the nature of the implementation strategies in the included studies. Furthermore, it enables investigation of whether the studies suffer from commonly reported problems in the current implementation research such as inconsistent labelling, poor descriptions, and unclear justification for specific implementation strategies. The actors are defined as the stakeholder delivering the strategy; the actions are defined as those actions enacted by the actors; action targets are the population targeted by the intervention and how the actions are supposed to impact this population; temporality is defined as the phased nature of implementation meaning at which stage was the strategy used relative to other stages; dose is defined as the frequency and intensity of the implementation strategy such as the amount of time spent with an external facilitator; and theoretical justification is defined as the justification or rationale for the implementation strategy, which can be theoretical, empirical, and/or pragmatical.

\section{Taxonomy for evaluating the implementation strategies}

We systematically investigated whether studies reported on the eight implementation outcomes prescribed by Proctor et al. [42]: acceptability (i.e. the perception among stakeholders that an intervention is agreeable), appropriateness (i.e. the perceived fit or relevance of the intervention in a setting or for a particular target audience or issue), feasibility (i.e. the extent to which an intervention can be carried out in a specific setting or organisation), adoption (i.e. the intention, initial decision, or action to try to employ a new intervention), penetration (i.e. the degree to which the population who is eligible to benefit from an intervention actually receives it), sustainability (i.e. the extent to which an intervention is maintained or institutionalised in a given setting), implementation costs (i.e. the incremental cost of the delivery strategy), and implementation fidelity (i.e. the extent to which an intervention is delivered as planned). We assessed implementation fidelity (IF), using the models of Carroll et al. [54].

\section{Statistical analysis}

Comparisons between groups for continuous outcomes were conducted using mean differences (MD) and their corresponding $95 \%$ confidence intervals and $p$ values. For binary outcomes, proportions or percentages were compared using chi-square tests. Most studies used regression analyses to compare outcomes between the study groups with adjustments for multiple comparisons, baseline, and confounding variables, and in these cases, we used the $p$ values reported by the study authors. However, differences in study designs, outcomes, the scale of measurements, and measurement times precluded meta-analysis. We, therefore, provide a narrative summary of the findings across studies.

\section{Results}

Summary of the searches

A flow consort diagram of the studies selected for inclusion is summarised in Fig. 1. A total of 702 records were identified from searches. After removal of duplicates and title and abstract screening, 218 articles were selected for further evaluation via full text; of these, 207 full-text articles were excluded, 172 were not from LMIC, 18 were led by professional providers, 8 had inappropriate study designs, and 3 were reviews or protocol papers. Thus, only eleven studies met the inclusion criteria and were included in the systematic review. These studies were published in the period from 2008 to 2019 based on patient populations in the following countries: South Africa $(n=2)$, Cameroon $(n=1)$, Uganda $(n=1)$, China $(n=2)$, Cambodia $(n=1)$, Argentina $(n=1)$, Guatemala $(n=1)$, Jamaica $(n=1)$, and Mali $(n=1)$. The included studies comprised four RCTs [50-53], one nonrandomised parallel arms intervention study [43], and six pretest-posttest studies [44-49]. The sample sizes in the studies varied from 19 to 2714; in total, there were 6090 participants in this review. Seven studies investigated support provided by peers, while the remaining three studies explored support provided by CHWs.

\section{Quality of included studies}

A summary of the risk of bias of included RCT selected studies by using the Cochrane tool is shown in Table 1 . Two studies (Zhong et al. [51] and Gagliardino et al. [52]) failed to report details about random sequence generation and also details of allocation concealment. Only one study (Debussche et al. [50]) described the use of blinding of participants and investigators, three studies (Zhong et al. [51] and Gagliardino et al. [52] and Mash et al. [53]) had high risk of bias in blinding of participants and personnel, and other studies did not report the detailed information. The outcomes assessor was reported to be blinded in one study (Debussche et.al 2018). Only one study (Mash et al.,2014) described the reasons for participants' withdrawals.

A summary of the risk of bias for the non-RCTs by using ROBINS-I tool is illustrated in Table 2 and was applied retrospectively. A serious risk of bias was assessed for all seven studies for the following domains: confounding, selection of participants, classification of interventions, and measurement of outcomes, and for four studies for selection of the reported results. As a result, our overall judgement was that all studies had serious risks of bias. 


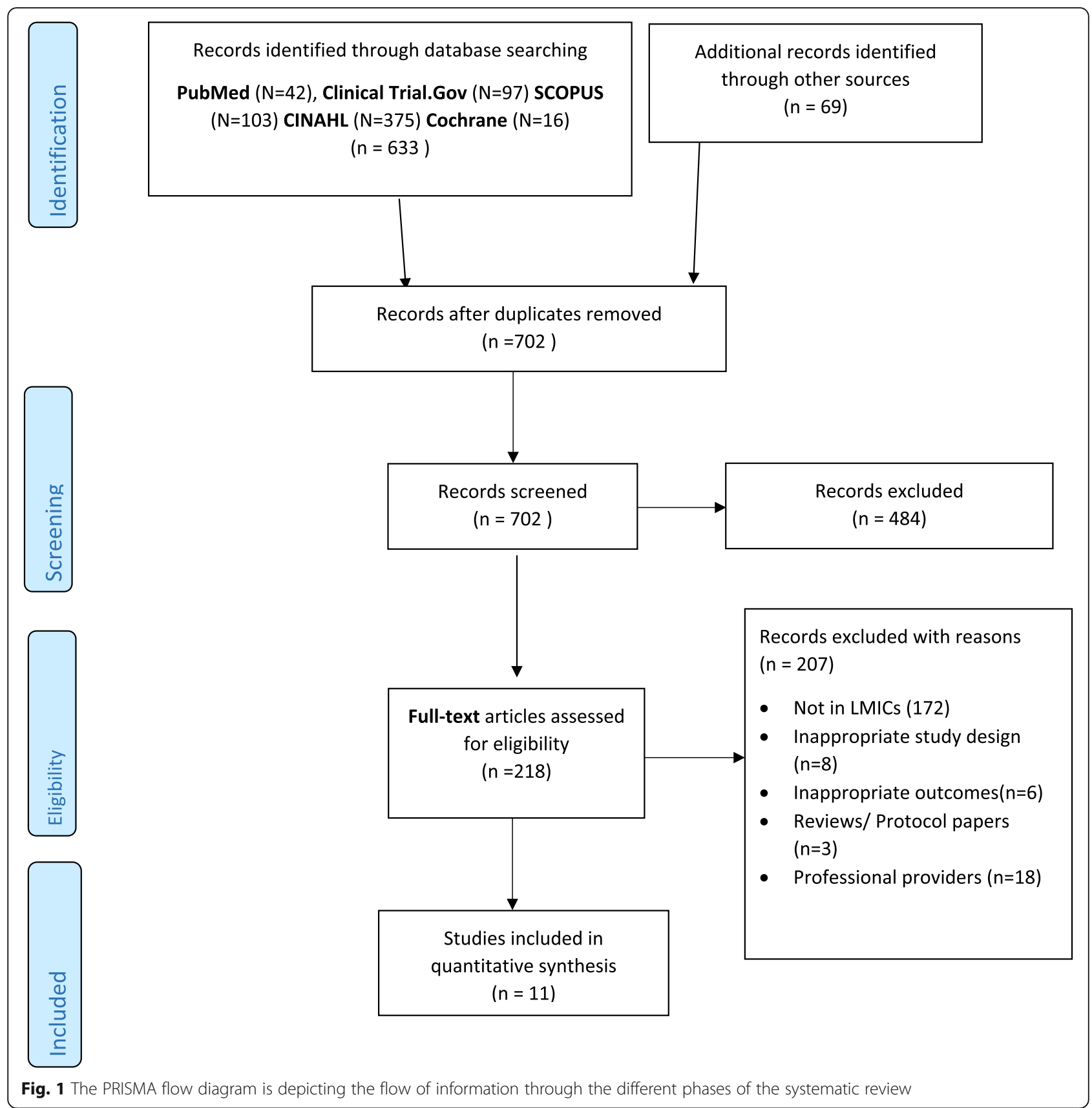

In the GRADE analysis, two studies were judged as having moderate quality $[51,53]$ (Table 3 ). The results did not fully answer our question, as well as showing imprecision for not properly implementing the COMPDSMPs; therefore, considering the overall risk of bias, only one study [50] was judged as having high-quality evidence for the question of this systematic review.

\section{Taxonomy of implementation of peer support strategies}

Table 4 illustrates the taxonomy of the peer/CHW support implementation strategies in the included studies based on the framework by Proctor et al. [41].

\section{Actor-who delivers the strategy?}

Across the studies, the actors providing the support varied; in eight studies, actors were peers [43-47, 50-52], while in three studies, the support was provided by CHWs $[48,49,53]$. In the peer-led interventions, peers were often volunteers selected based on their knowledge, experience, and adherence to medication and lifestyle changes and thus functioned as role models for patients. In two studies $[47,50]$, peers were deliberately selected based on their everyday life challenges being similar to those of the patients, while another study did not describe the skill-level of the peers [44]. No description of 
Table 1 Risk of bias for included RCTs

\begin{tabular}{|c|c|c|c|c|c|c|}
\hline Authors, year & $\begin{array}{l}\text { Selection bias, } \\
\text { random sequence } \\
\text { generation }\end{array}$ & $\begin{array}{l}\text { Selection bias } \\
\text { (allocation } \\
\text { concealment) }\end{array}$ & $\begin{array}{l}\text { Detection bias, } \\
\text { blinding (outcome } \\
\text { assessment) }\end{array}$ & $\begin{array}{l}\text { Attrition bias, } \\
\text { incomplete } \\
\text { outcome data }\end{array}$ & $\begin{array}{l}\text { Reporting bias, } \\
\text { selective } \\
\text { reporting }\end{array}$ & $\begin{array}{l}\text { Performance bias, } \\
\text { blinding (participants and } \\
\text { personnel) }\end{array}$ \\
\hline $\begin{array}{l}\text { Debussche } \\
\text { et al. } 2018 \\
\text { [50] }\end{array}$ & Low & Low & Low & Low & Low & Low \\
\hline $\begin{array}{l}\text { Zhong et al. } \\
2015 \text { [51] }\end{array}$ & NCR & $N C R$ & High & High & Low & NCR \\
\hline $\begin{array}{l}\text { Gagliardino } \\
\text { et al. } 2014 \\
\text { [52] }\end{array}$ & $N C R$ & $N C R$ & High & NCR & Low & High \\
\hline $\begin{array}{l}\text { Mash et al. } \\
2014 \text { [53] }\end{array}$ & Low & $N C R$ & High & Low & Low & High \\
\hline
\end{tabular}

NCR no clear risk

the CHWs in the three included studies was given, other than they were non-professional health workers (i.e. without a formal health tertiary education) from the local community. In all the studies, the peers/CHWs received training prior to commencing the intervention; most training courses lasted a few days. In one study, Eggermont [45], training lasted 6 weeks. However, in this study, peers also played crucial roles in screening and monitoring clinical measures in patients in addition to providing DSME and DSMS.

\section{Actions-which actions do the actors enact?}

Across the studies, the peers/CHW aimed at equipping the patients with knowledge, support, and skills to manage their diabetes. Thus, the peers/CHW provided
DSMS and DSME. In most of the studies, peers/CHW led the group and discussion meetings $[43,45,46,48-$ 52] as well as more informal activities such as organising physical activities and cooking classes. In all studies, peers/CHW provided emotional and/or social support through informal contact with the patient through inperson interactions and/or telephone contact. In two studies, emotional and social support formed the basis of the intervention $[44,47]$. Two studies $[44,46]$ emphasised a deep-grounded one-to-one contact; where peer educators in Baumann et al. [44] were paired with patient peers, peers facilitated the establishment of buddy pairs between patients in Rotheram-Borus et al. [46]. In the remaining interventions, the actions by peers/CHWs targeted both groups and individuals depending on the

Table 2 Results of the assessment of risk of bias in included non-randomized studies by using the ROBINS-I assessment tool

\begin{tabular}{|c|c|c|c|c|c|c|c|c|}
\hline Study ID & $\begin{array}{l}\text { 1. Bias } \\
\text { caused by } \\
\text { confounding }\end{array}$ & $\begin{array}{l}\text { 2. Bias } \\
\text { caused by } \\
\text { selection of } \\
\text { participants }\end{array}$ & $\begin{array}{l}\text { 3. Bias caused } \\
\text { by } \\
\text { classification } \\
\text { of } \\
\text { interventions }\end{array}$ & $\begin{array}{l}\text { 4. Bias caused by } \\
\text { deviations from } \\
\text { intended } \\
\text { interventions }\end{array}$ & $\begin{array}{l}\text { 5. Attrition bias } \\
\text { caused by } \\
\text { missing data }\end{array}$ & $\begin{array}{l}\text { 6. Detection bias } \\
\text { caused by } \\
\text { measurement of } \\
\text { outcomes }\end{array}$ & $\begin{array}{l}\text { 7. Reporting bias } \\
\text { caused by } \\
\text { selection of the } \\
\text { reported results }\end{array}$ & $\begin{array}{l}\text { Overall } \\
\text { judgement }\end{array}$ \\
\hline $\begin{array}{l}\text { Assah et al. } \\
\text { [43] }\end{array}$ & Serious & Serious & Serious & Low & No information & Serious & Serious & Serious \\
\hline $\begin{array}{l}\text { Baumann } \\
\text { et al. [44] }\end{array}$ & Serious & Serious & Serious & Low & $\begin{array}{l}\text { Low (information } \\
\text { on reasons for } \\
\text { missing data } \\
\text { provided) }\end{array}$ & Serious & Serious & Serious \\
\hline $\begin{array}{l}\text { Eggermont } \\
{[45]}\end{array}$ & Serious & Serious & Serious & Low & $\begin{array}{l}\text { Low (information } \\
\text { on reasons for } \\
\text { missing data } \\
\text { provided) }\end{array}$ & Serious & Moderate & Serious \\
\hline $\begin{array}{l}\text { Rotheram- } \\
\text { Borus et al. } \\
{[46]}\end{array}$ & Serious & Serious & Serious & Low & Serious & Serious & Serious & Serious \\
\hline Shen [47] & Serious & Serious & Serious & Low & No information & Serious & Low & Serious \\
\hline $\begin{array}{l}\text { Less et al. } \\
\text { [48] }\end{array}$ & Serious & Serious & Serious & Low & $\begin{array}{l}\text { Low (information } \\
\text { on reasons for } \\
\text { missing data } \\
\text { provided) }\end{array}$ & Serious & Low & Serious \\
\hline $\begin{array}{l}\text { Micikas } \\
\text { et al. [49] }\end{array}$ & Serious & Serious & Serious & Low & No information & Serious & Serious & Serious \\
\hline
\end{tabular}


Table 3 Assessment of quality of evidence (GRADE) in the included studies

\begin{tabular}{|c|c|c|c|c|c|c|c|}
\hline Study ID & Study design & Study limitation & Inconsistency & Indirectness & Imprecision & Bias & Overall quality \\
\hline Debussche et al. [50] & $\mathrm{RCT}$ & $\sqrt{ }$ & $\sqrt{ }$ & $\sqrt{ }$ & $\sqrt{ }$ & $\sqrt{ }$ & ++++ \\
\hline Zhong et al. [51] & $\mathrm{RCT}$ & $\sqrt{ }$ & $x$ & $\sqrt{ }$ & $\sqrt{ }$ & $x$ & +++ \\
\hline Gagliardino et al. [52] & $\mathrm{RCT}$ & $x$ & $x$ & $\sqrt{ }$ & $\sqrt{ }$ & $x$ & ++ \\
\hline Mash et al. [53] & $\mathrm{RCT}$ & $\sqrt{ }$ & $x$ & $\sqrt{ }$ & $\sqrt{ }$ & $X$ & +++ \\
\hline Assah et al. [43] & Non-RCT with control & $x$ & $x$ & $\sqrt{ }$ & $\sqrt{ }$ & $\mathrm{x}$ & ++ \\
\hline Baumann et al. [44] & UCBA (one-group) & $x$ & $x$ & $\sqrt{ }$ & $\sqrt{ }$ & $\mathrm{x}$ & ++ \\
\hline Micikas et al. [49] & UCBA (one-group) & $\sqrt{ }$ & $x$ & $\sqrt{ }$ & $x$ & $x$ & ++ \\
\hline Eggermont [45] & UCBA (one-group) & $x$ & $x$ & $\sqrt{ }$ & $\sqrt{ }$ & $\mathrm{x}$ & ++ \\
\hline Rotheram-Borus et al. [46] & UCBA (one-group) & $x$ & $x$ & $\sqrt{ }$ & $\sqrt{ }$ & $x$ & ++ \\
\hline Shen [47] & CBA (comparison group) & $\sqrt{ }$ & $x$ & $\sqrt{ }$ & $\sqrt{ }$ & $x$ & ++ \\
\hline Less et al. [48] & CBA (comparison group) & $\sqrt{ }$ & $\mathbf{x}$ & $\sqrt{ }$ & $\sqrt{ }$ & $x$ & ++ \\
\hline
\end{tabular}

$\sqrt{ }$ no serious limitations; $X$ serious limitations, for overall quality of evidence: + very low; ++ low; +++ moderate; ++++ high; $R C T$ randomize control trials; $C B A$ controlled before and after studies; UCBA uncontrolled before and after

form of activity. In terms of the types of studies, the interventions were group-based in the four RCTs [50-53] and in five of the seven non-RCT studies; the remaining two non-RCTs were one-to-one interventions [44, 48].

\section{Targets of action-who/what are the actors attempting to impact?}

All interventions aimed at enhancing emotional and social support for and improving self-care behaviours and management in adults with diabetes. Furthermore, by improving emotional/social support and selfmanagement, the studies aimed to improve clinical outcomes such as glycaemic control, blood pressure, and BMI. Most of the studies targeted T2DM patients exclusively, while two studies did not distinguish between T1DM and T2DM [45, 46]. In two studies, the intervention specifically targeted patients without major comorbidities [51, 52], while the intervention in one study [45] targeted diabetes patients, of whom some also had hypertension. In one study, the intervention targeted older adults (60 years and above) exclusively [47].

\section{Temporality-when does the strategy take place?}

In all studies, the actions by the actors (i.e. peers/CHW) were commenced following their own training. Only a single study, Shen outlined the relative time from completion of peer/CHW training and the commencement of the interventions [47].

\section{Dose-what is the frequency and intensity of the intervention?}

The intervention strategies varied in duration and frequency; the strategies ranged from weekly 40-min group discussions [52] to weekly teaching sessions (90-120 min each) and group discussions [47]. The follow-up periods varied between 3 months to 24 months (3 months
[47], 4 months [44, 49], 6 months [43, 48, 55], 12 months [50-53], and 24 months [46]).

\section{Justification - which (theoretical, empirical, pragmatic) justification is provided for the choice of implementation strategy?}

Most of the studies justified the utilisation of a peer/ $\mathrm{CHW}$-based intervention for diabetes by referring to existing literature, which highlights peer/CHW-based interventions can contribute to improving chronic conditions. Furthermore, most studies justified the peer/CHW-based intervention by referring to studies showing that such interventions provide a low-cost, flexible means to improve care for chronic conditions in resource-constrained health systems. A few studies also conducted formative research including focus groups and individual interviews in the communities to aid the development of interventions. The formative research illustrated that peer/CHW interventions were desired and/or suited for the given communities [46, 47, 49, 51].

\section{Implementation outcomes}

A comprehensive assessment of implementation outcomes, in terms of acceptability, adoption, appropriateness, feasibility, implementation cost, penetration, and sustainability, is shown in Table 5. Most of the included studies assessed only a few of these outcomes. As an example, implementation cost was only measured in one study [48], while implementation adoption, appropriateness, and penetration were measured in two studies [50, 51]. Acceptability and feasibility were most commonly measured (both were measured in five studies [45, 46, 49-51]). 


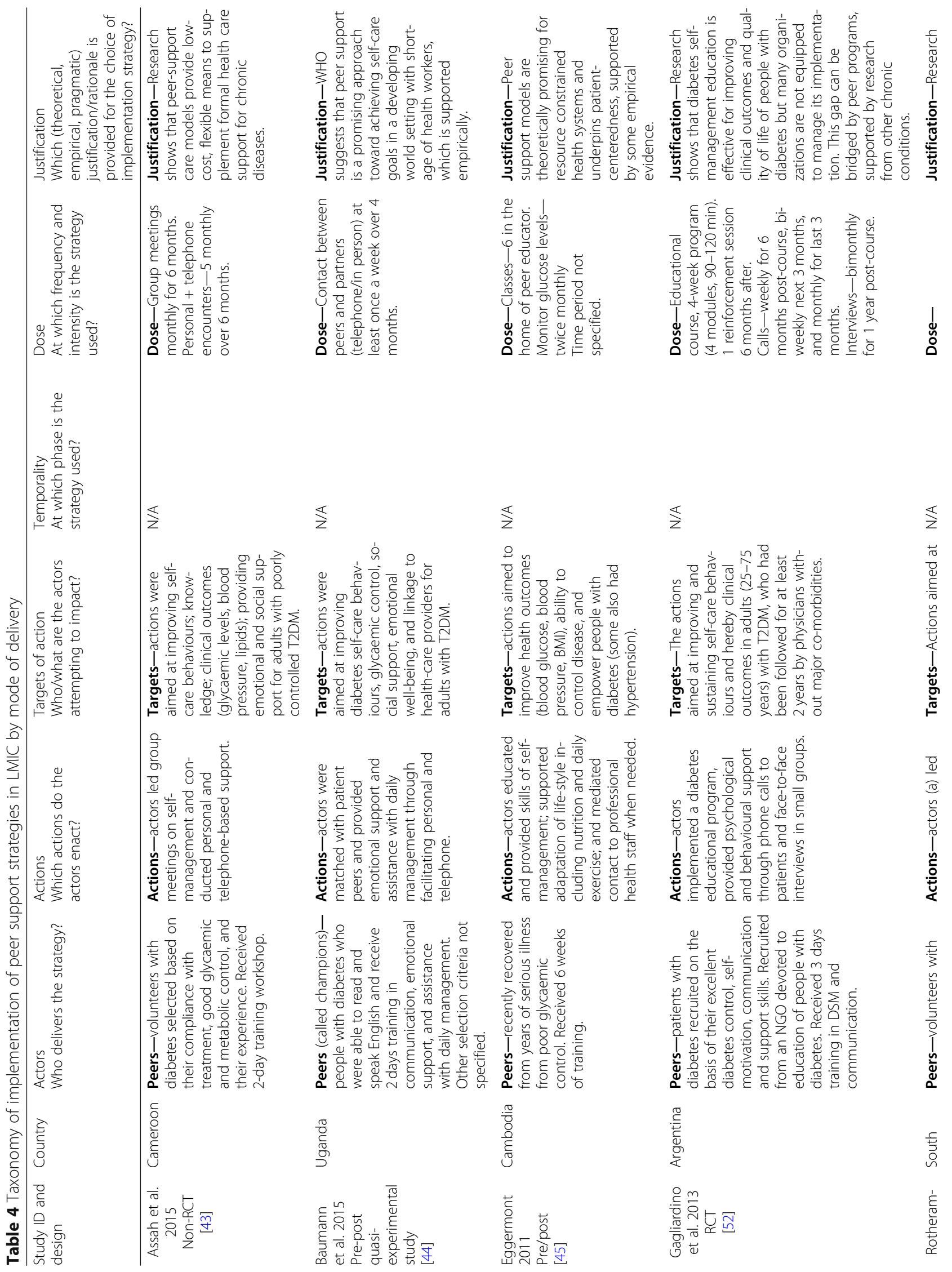




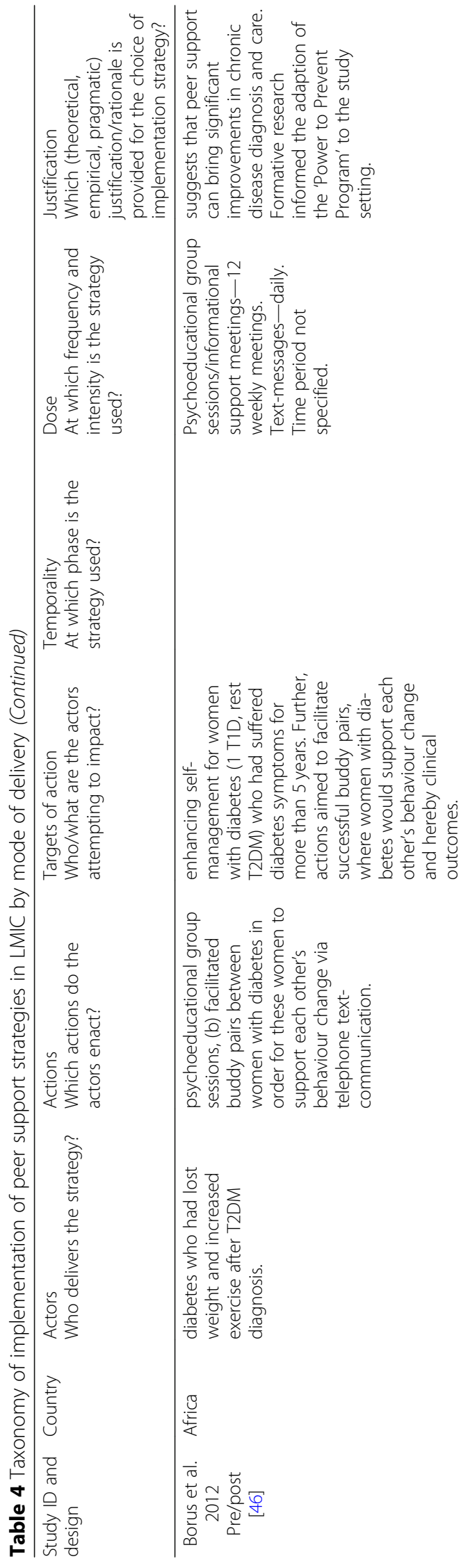

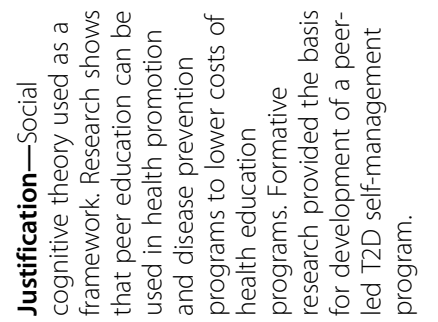

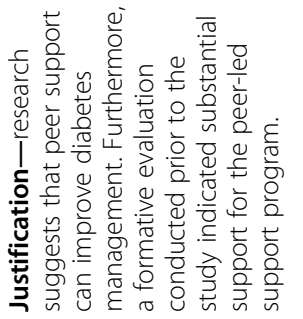

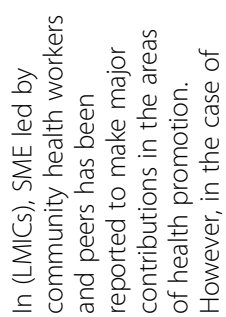
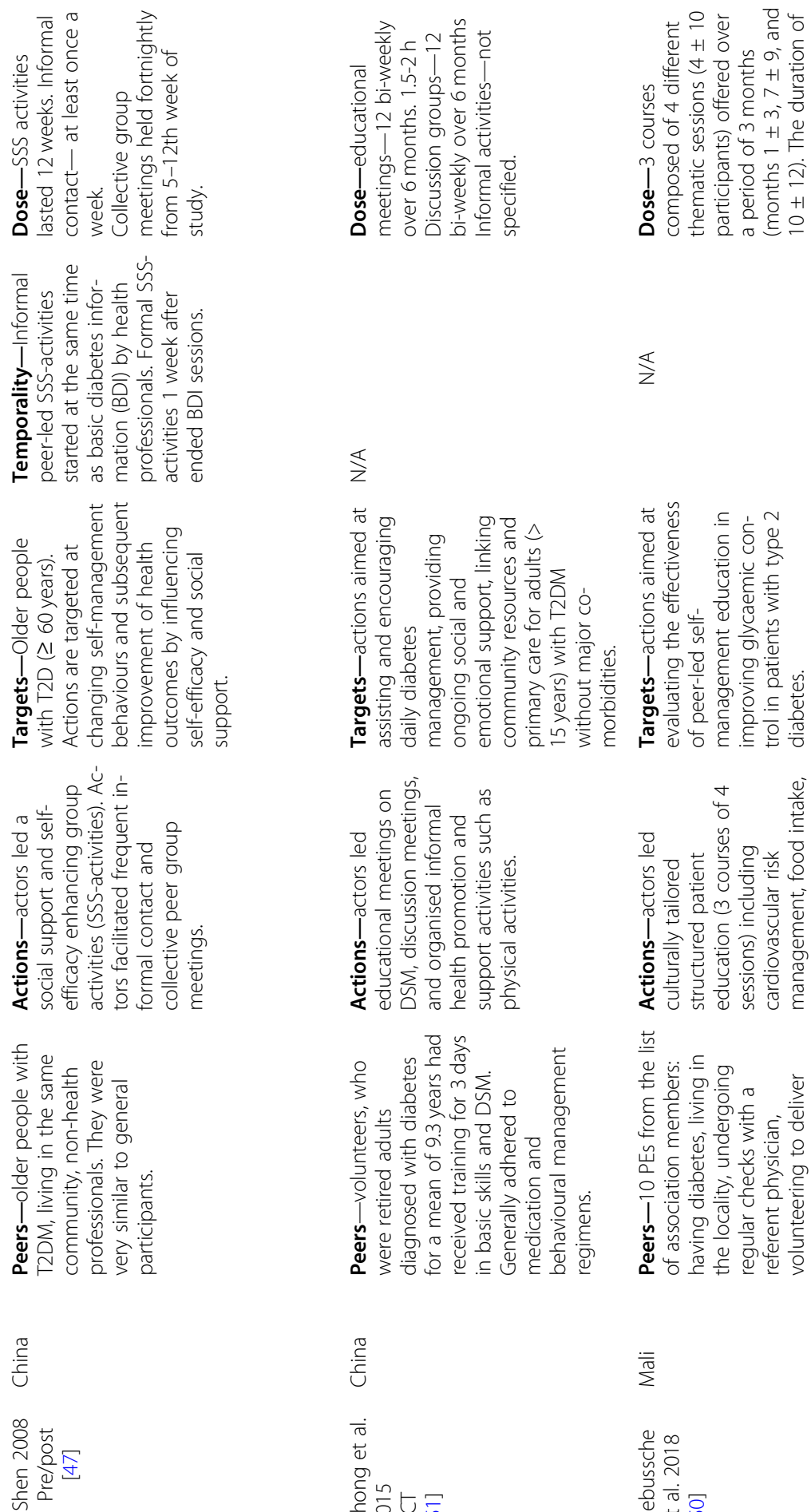

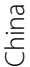

$\frac{i \bar{\pi}}{2}$

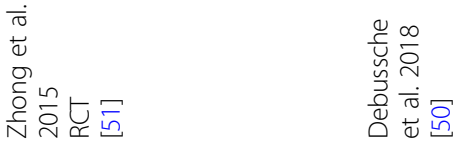




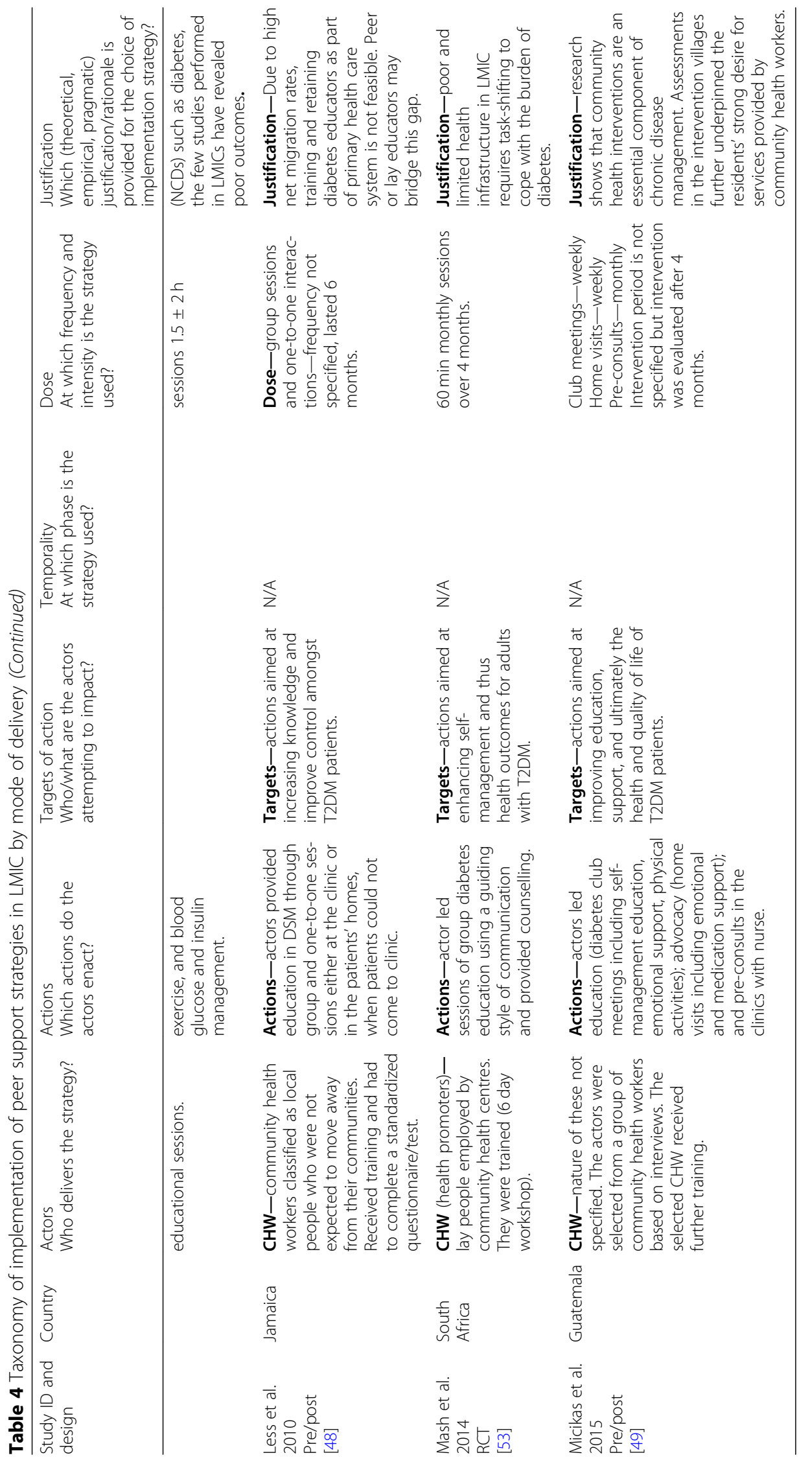




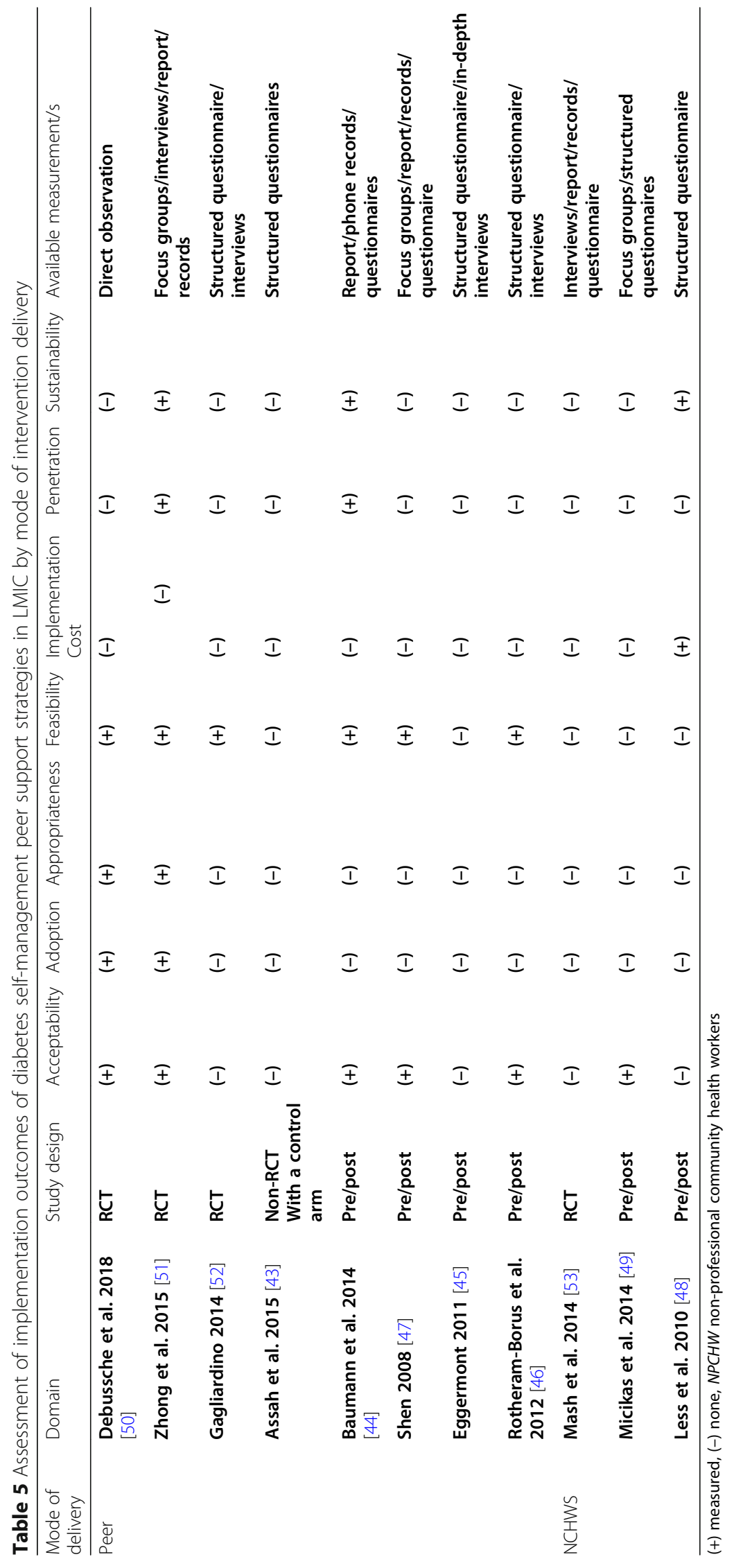


Diabetes-related outcomes

The diabetes-related outcomes described by study design, (RCT and non-RCT design) are summarised in Table 6 and detailed below.

\section{Randomised controlled trials Clinical outcomes}

HbA1c Of the 4 RCTs, only 2 studies (Mash et al. and Debussche et al.) assessed HbA1c. In one study, the mean reduction in $\mathrm{HbA} 1 \mathrm{c}$ of $1.05 \%$ between intervention and control groups was both statistically and clinically significant [50].
Fasting glucose and 2-h postprandial glucose (FPG/ PPG) Zhong et al. was the only RCT which examined changes in fasting glucose levels. The study showed a reduction from 7.68 to $6.76 \mathrm{mmol} / \mathrm{L}$ for the intervention group, while those in the control groups exhibited a slight increase from 6.38 to $6.66 \mathrm{mmol} / \mathrm{L}$. [51]. The difference between these two patterns was statistically significant $(p<.001)$, but the authors did not report on its clinical relevance.

Blood pressure Two of three RCTs, Zhong et al. and Mash et al. [51, 53], reported on blood pressure. These studies found significant reductions in systolic blood pressure (SBP) and diastolic blood pressure (DBP) in the

Table 6 Summary of intervention effects on clinical, behavioural and psychological outcomes by study design

\begin{tabular}{|c|c|c|c|c|c|c|c|c|c|c|c|}
\hline Authors, year & $\begin{array}{l}\text { Debussche } \\
\text { et al., } 2018 \\
\text { [50] }\end{array}$ & $\begin{array}{l}\text { Zhong } \\
\text { et al. } \\
2015 \\
{[51]}\end{array}$ & $\begin{array}{l}\text { Gagliardino } \\
2014 \text { et al. } \\
\text { [52] }\end{array}$ & $\begin{array}{l}\text { Mash } \\
\text { et al. } \\
2014 \\
{[53]} \\
\end{array}$ & $\begin{array}{l}\text { Assah } \\
\text { et al. } \\
2015 \\
{[43]}\end{array}$ & $\begin{array}{l}\text { Micikas } \\
\text { et al. } \\
2014 \text { [49] }\end{array}$ & $\begin{array}{l}\text { Baumann } \\
\text { et al. } \\
2014 \text { [44] }\end{array}$ & $\begin{array}{l}\text { Shen } 2008 \\
{[47]}\end{array}$ & $\begin{array}{l}\text { Eggermont } \\
2011 \text { [45] }\end{array}$ & $\begin{array}{l}\text { Rotheram- } \\
\text { Borus } \\
\text { et al. } 2012 \\
{[46]} \\
\end{array}$ & $\begin{array}{l}\text { Less et al. } \\
2010 \text { [48] }\end{array}$ \\
\hline Design & $\mathrm{RCT}$ & $\mathrm{RCT}$ & RCT & $\mathrm{RCT}$ & $\begin{array}{l}\text { Non- } \\
\text { RCT } \\
\text { with } \\
\text { control }\end{array}$ & $\begin{array}{l}\text { Pretest- } \\
\text { posttest } \\
\text { (one } \\
\text { group) }\end{array}$ & $\begin{array}{l}\text { Pretest- } \\
\text { posttest } \\
\text { (one } \\
\text { group) }\end{array}$ & $\begin{array}{l}\text { Pretest- } \\
\text { posttest with } \\
\text { comparison } \\
\text { group }\end{array}$ & $\begin{array}{l}\text { Pretest } \\
\text { posttest } \\
\text { (one group) }\end{array}$ & $\begin{array}{l}\text { Pretest- } \\
\text { posttest } \\
\text { (one } \\
\text { group) }\end{array}$ & $\begin{array}{l}\text { Pretest- } \\
\text { posttest with } \\
\text { comparison } \\
\text { group }\end{array}$ \\
\hline Sample size & $\begin{array}{l}n=151 \\
C 76 \\
175\end{array}$ & $\begin{array}{l}n= \\
229 \\
C 94 \\
l 135\end{array}$ & $\begin{array}{l}n=198 \\
C 105 \\
193\end{array}$ & $\begin{array}{l}n= \\
1570 \\
C 860 \\
1710\end{array}$ & $\begin{array}{l}n= \\
200 \\
C 96 \\
196\end{array}$ & $n=100$ & $n=46$ & $\begin{array}{l}n=181 \\
C 89 \\
192\end{array}$ & $n=3078$ & $n=19$ & $\begin{array}{l}n=318 \\
C 159 \\
l 159\end{array}$ \\
\hline $\begin{array}{l}\text { Duration of } \\
\text { diabetes } \\
\text { (year) }\end{array}$ & NR & 9.3 & 6 & $N R$ & NR & NR & 6.7 & NR & NR & NR & $5-21$ \\
\hline $\begin{array}{l}\text { Follow-up } \\
\text { (months) }\end{array}$ & 12 & 12 & 12 & 12 & 6 & 4 & 4 & 3 & 24 & 6 & 6 \\
\hline $\mathrm{HbA} 1 \mathrm{C}$ & $\downarrow$ & NR & $N R$ & $\leftrightarrow$ & $\downarrow$ & $\downarrow$ & $\downarrow$ & NR & NR & NR & $\downarrow$ \\
\hline FBG/PPG & $N R$ & $\downarrow$ & NR & $N R$ & NR & $N R$ & NR & NR & $\downarrow$ & NR & $N R$ \\
\hline BP & NR & $\downarrow$ & NR & $\downarrow$ & NR & NR & $\downarrow \mathrm{DBP}$ & NR & $\downarrow$ & NR & NR \\
\hline BMI & $\downarrow$ & $\downarrow$ & $\leftrightarrow$ & $\leftrightarrow$ & NR & $\leftrightarrow$ & NR & NR & $\leftrightarrow$ & $\leftrightarrow$ & $\leftrightarrow$ \\
\hline $\begin{array}{l}\text { Diabetes } \\
\text { symptoms }\end{array}$ & NR & NR & $\leftrightarrow$ & NR & NR & NR & NR & NR & NR & NR & NR \\
\hline $\begin{array}{l}\text { Clinical visits/ } \\
\text { hospitalis- } \\
\text { ation }\end{array}$ & NR & NR & $N R$ & NR & NR & NR & NR & $\leftrightarrow$ & NR & NR & NR \\
\hline $\begin{array}{l}\text { Self- } \\
\text { management } \\
\text { activities }\end{array}$ & $N R$ & $\leftrightarrow$ & NR & $\leftrightarrow$ & $\uparrow$ & NR & $\leftrightarrow$ & $\uparrow$ & NR & NR & $N R$ \\
\hline $\begin{array}{l}\text { Physical } \\
\text { activity }\end{array}$ & NR & NR & $\leftrightarrow$ & NR & NR & $\leftrightarrow$ & NR & NR & NR & NR & $N R$ \\
\hline Self-efficacy & NR & $\uparrow$ & $N R$ & $\leftrightarrow$ & NR & NR & NR & $\uparrow$ & NR & NR & NR \\
\hline $\begin{array}{l}\text { Diabetes } \\
\text { knowledge }\end{array}$ & NR & $\uparrow$ & $\uparrow$ & NR & NR & $\uparrow$ & NR & NR & NR & NR & NR \\
\hline Depression & NR & NR & $\leftrightarrow$ & $\leftrightarrow$ & NR & NR & NR & $\leftrightarrow$ & NR & $\leftrightarrow$ & NR \\
\hline $\begin{array}{l}\text { Social } \\
\text { support }\end{array}$ & $N R$ & NR & NR & NR & NR & NR & NR & $\uparrow$ & NR & $\uparrow$ & NR \\
\hline Quality of life & NR & NR & NR & $\leftrightarrow$ & NR & NR & NR & $\leftrightarrow$ & NR & NR & NR \\
\hline
\end{tabular}

$\leftrightarrow$ no statistical significant differences, $\uparrow$ significant increase, $\downarrow$ significant decrease, NR not reported, HbA1C glycated hemoglobin, FBG/PPG fasting glucose and 2h postprandial glucose, $B P$ blood pressure, $B M I$ body mass index, $N R$ not reported 
peer/CHW-led interventions compared to the control groups.

Zhong et al. [51] reported a significant reduction in SBP in their interventional group $(136-128 \mathrm{mmHg})$ compared to the control group $(130-131 \mathrm{mmHg})$ and in DBP (intervention 82.5-79.1 mmHg; control 79.0-78.6 $\mathrm{mmHg}$ ). Mash et al. [53] reported a weighted mean SBP reduction of $4.65 \mathrm{mmHg}$ ( $95 \% \mathrm{CI}-9.18$ to -0.12 ), which was not statistically significant. Further, a weighted mean DBP reduction of $-3.30 \mathrm{mmHg}(95 \% \mathrm{CI}$ - 5.35 to -1.26$)$ was statistically significant.

Body mass index Two RCTs measured BMI, which was reduced in the peer-led intervention groups $[50,51]$.

Diabetes symptoms Only Gagliardino et al. reported changes in classical diabetes symptoms (polydipsia, polyuria, polyphagia, pruritus, and asthenia). The symptoms were statistically significantly reduced in both control and intervention groups between baseline and 12 months with no significant differences between control and intervention reductions [52]. The authors did not report whether these findings were clinically relevant.

\section{Behavioural health outcomes}

Self-management care outcome Only two RCT studies reported on self-management care activities. Zhong et al. and Mash et al. [51,53] found no significant differences in self-management practices relating to diet, physical activity, glucose monitoring, and medication adherence.

Physical activity Two of the three RCTs reported on physical activity. Gagliardino et al. [52] demonstrated a significant reduction in the number of participants practicing regular physical activity in control (56 to 37\%, $p=$ 0.0006), but not the COMP-DSMP intervention group (69 to $60 \%, p=0.221$ ). Notably, there was a significant difference in the reduction (in \%) between the two groups (19\% versus 9\%, $p=0.035)$. Zhong et al. [51] reported no improvement in self-reported physical activity.

\section{Psychological health outcomes}

Self-efficacy Although self-efficacy for diabetes management was measured using different scales, two RCT studies reported increased self-efficacy in the intervention group compared to the control group when measured at 6 to 12 months. Zhong et al. [51] found significant improvements in self-efficacy with the intervention in two out of six sites, where a COMP-DSMP was implemented. However, Mash et al. [53] reported the COMP-DSMP intervention did not improve psychological health outcomes including self-efficacy.
Diabetes knowledge Two RCT studies reported on diabetes knowledge. Zhong et al. [51] found statistically significant improvements at 12 months' follow-up in a knowledge domain made up of twelve items (four concerning glucose, three concerning diabetic complications, two concerning diet, and three concerning insulin). However, the control group's knowledge diminished from baseline. Gagliardino et al. showed that the attendees' knowledge increased significantly $(p<0.01)$ in both groups, but without any significant difference between intervention and control groups.

Depression, diabetes-related distress, and quality of life Gagliardino et al. reported on diabetes-related distress, while Mash et al. reported on depression. Neither study reported significant differences in these measurements in the intervention and control groups at baseline to 12 months $[52,53]$. Zhong et al. did not report on any of these measures, and none of the RCTs reported on quality of life.

\section{Pre-test/post-test and non-RCTs Clinical outcomes}

HBA1c Four studies, Assah et al., Micikas et al., Baumann et al., and Less et al. [43, 44, 48, 49] reported HbA1c as an outcome measure. Assah et al. [43] reported a greater reduction in HbA1c in the peer-led intervention than the control group (difference $=-1.7 \%$, $95 \% \mathrm{CI}-2.2$ to $-1.3 \%, p<0.001)$. The other three studies with significant improvements were quasiexperimental in design. Micikas et al. and Baumann et al. [44, 49] reported the mean HbA1c decreased from $10.1 \%$ and $11.1 \%$ at baseline to $8.9 \%$ and $8.3 \%$ at 4 months $(p=0.01$ and $p=0.005)$ respectively. Less et al. reported a reduction of $0.6 \%$ in mean $\mathrm{HbA1c}$ in the intervention group between baseline and 6-month values and an increase of $0.6 \%$ in the control group, with the difference being statistically significant after controlling for potential confounders $(p<0.05)$ [48].

Fasting blood glucose levels Only Eggermont et al. reported on blood glucose outcomes. The study demonstrated a statistically significant reduction in fasting blood glucose $(10.0$ to $7.7 \mathrm{mmol} / \mathrm{l}, p<0.001) 2$ years after baseline [45].

Blood pressure Two studies reported on blood pressure. Eggermont et al. identified significant reductions in systolic (134 to $124 \mathrm{mmHg}, p<0.001)$ and diastolic $(85$ to $77 \mathrm{mmHg}, p<0.001)$ blood pressure [45]. In contrast, Baumann et al. [44] reported that diastolic (85-76 $\mathrm{mmHg}, p<0.001)$ but not systolic $(146-140 \mathrm{mmHg}, p=$ 
0.25 ) blood pressure decreased significantly in the intervention group compared to the control group.

BMI There was no difference found between- or withingroup changes in BMI in the four studies where BMI was assessed [45, 46, 48, 49].

\section{Behavioural health outcomes}

Self-management care outcome Three studies reported on self-management care activities. Assah et al. [43] found a significantly increased level of selfcare activities in the intervention compared to the control group $(p<0.001)$. Baumann et al. [44] reported that the adherence to the eating plan improved from pre- to post-intervention $(p<0.005)$, which was measured regarding a 'healthy eating index' created by the authors. However, there were no significant pre/post-intervention changes in physical activity, missed medication, helpfulness of social support, emotional well-being, confidence, and barriers to self-care. Shen [47] reported that overall selfmanagement activities were significantly higher in the intervention group compared to the control group. However, self-management of diet and medication did not differ significantly between the two groups at 4 and 12 weeks. These analyses were adjusted for baseline variables and multiple comparisons.

Only Shen [47] reported a reduction in the number of visits to a doctor (MD $-0.73, p=0.03$ ) and a community health centre (MD $-0.60, p=0.03)$ in the intervention compared to the control group. However, there were no significant differences in the number of visits to the emergency room, the frequency of hospitalisation, or the days of hospitalisation between the groups at 4 or 12 weeks.

Physical activity One study, Micikas et al. [49], reported on physical activity. The study did not observe significant changes in the proportion of patients who exercised for $\geq 30$ min per day after 4 months of the intervention (20 to $18 \%, p=0.811$ ).

\section{Psychological health outcomes}

Self-efficacy One study reported on self-efficacy. Baumann et al. [44] measured various aspects of self-efficacy including overall self-efficacy and self-efficacy relating to diet, exercise, medication use, blood glucose testing, foot care, and hyperglycaemia/hypoglycaemia. At 4 weeks and 12 weeks, overall self-efficacy (both $p<0.021$ ) and self-efficacy relating to blood glucose testing (both $p<$ 0.005), foot-care (both $p<0.001$ ), and hyper/ hypoglycaemia (both $p<0.001$ ) were significantly higher in the intervention compared to the control group.

Diabetes knowledge One study reported on diabetes knowledge. Micikas et al. [49] reported that the intervention (over 4 months) significantly improved diabetes knowledge about targets for $\mathrm{HbA1C}$ (6 to $42 \%, p=0.001$ ), fasting blood glucose (19 to 87\%, $p=0.001$ ), and the foods that raise blood glucose levels (13 to $31 \%, p=0.032$ ). However, knowledge about the impact of emotions on blood glucose levels did not improve $(p=0.687)$.

Depression, diabetes distress, and quality of life Two studies reported on these measures. Shen [47] measured depressive status subdivided into 'overall depressive status', 'unhappy status', 'somatic status', 'interpersonal status', and 'depressed affect status'. The mean score for 'unhappy status' decreased significantly in the intervention group between 4 and 12 weeks $(p=0.037)$, while it did not change in the control group $(p=0.26)$. However, there were no significant differences between the intervention and control groups regarding 'overall depressive status', 'somatic', 'interpersonal', and 'depressed affect status'. Rotheram-Borus et al. [46] evaluated diabetes distress in terms of coping skills, which was significantly improved between baseline and 3 months, but not between 3 and 6 months. Furthermore, spiritual hope decreased between 3 and 6 months $(p<0.01)$.

Social support Two studies reported on social support. Shen [47] identified that the intervention group had significantly higher overall social support (both $p<0.001$ ), information and emotional support (both $p<0.001$ ), positive interaction (both $p<0.001$ ), and affectionate support (both $p<0.001$ ) compared to the control group assessed at 4 and 12 weeks. However, the peer intervention failed to improve tangible support significantly (include assisting with transportation, helping with household chores, helping to prepare food, providing physical care, and providing financial help) at the same time intervals 4 and 12 weeks. Rotheram-Borus et al. reported improvements in social support $(p<0.01)$ and positive-action coping style $(p<$ $0.01)$ after 3 months [46].

Implementation fidelity of all the included studies Implementation fidelity refers to the extent to which a proposed intervention is enacted as designed. This measure is essential to determine to which extent the intervention in question is the primary mechanism underlying any changes observed [42, 54]. Table 7 summarises the adherence, moderators, and assessment fidelity of the included studies in this review. The moderators of fidelity refer to factors which may influence or moderate the degree of fidelity with which an 


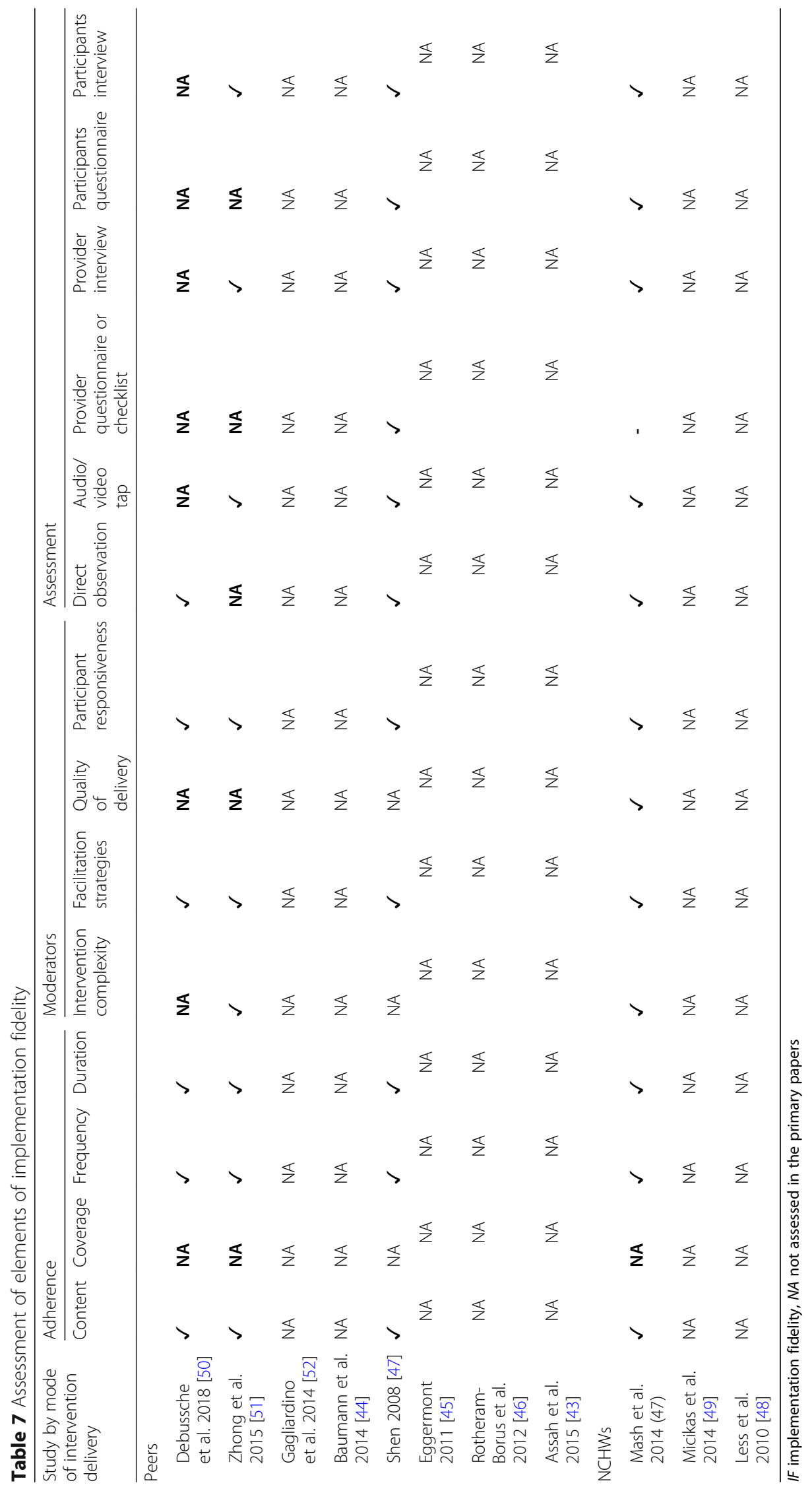


intervention is implemented such as intervention complexity, facilitation strategies, quality of delivery, and participant responsiveness [54, 55]. We were able to monitor fidelity in four studies, which had published protocols $[47,50,51,53]$. The most frequently used indicator of fidelity was adherence (to the content, frequency, and duration of the intervention) $[47,51,53]$. Four studies $[47,50,51,53]$ refer to facilitating strategies to increase the implementation quality. In one study [53], the quality of the program delivery was used as a moderator. Overall, three studies $[47,51,53]$ used a questionnaire or interviews completed by the participants and providers. Three studies [47, 50,53] combined a direct observation, recording of sessions, and selfreported measures (questionnaire or interviews completed by the participants and providers) to assess the adherence to the program content.

\section{Discussion}

This systematic review found that COMP-DSMPs were inconsistently associated with improvements in clinical $[43,47,48,50-53]$ behavioural $[43,44,52]$, and psychological $[43,44,51-53]$ outcomes in LMIC. There was high variability in reported outcomes. As a consequence, meaningful meta-analysis or comparisons were not possible. The included studies only assessed short-term outcomes, and no 'hard-endpoints' in terms of comorbidity, microvascular, macrovascular events, and mortality were reported.

Most included studies were of low-quality design with significant risks of bias particularly in relation to the blinding of outcomes. Furthermore, the majority of the non-RCT studies did not address issues surrounding selection bias or gave insufficient information regarding the selection process. The strategies employed were often not described in much detail and were poorly or not assessed regarding implementation fidelity. Finally, most of the studies reporting on clinical outcomes only evaluated the outcomes in terms of statistical significance and not clinical relevance. These results are discussed here in terms of implications for health care delivery, as well as implications for future design and implementation of studies of COMP-DSMPs in diabetes care delivery in LMIC.

Current literature, mainly from HIC, supports the findings from this review that effects of COMP-DSMPs are equivocal. A systematic review by Webel et al. reported major heterogeneity between studies both in outcomes and designs [55], while Dale et al. reported that peer-support seemed to benefit some adults living with diabetes, but suggested that the evidence was inconsistent and inadequate to support firm recommendations [56]. Large RCTs in HIC $[57,58]$ have also reported modest benefits for some, but not all outcomes assessed.
Throughout our analysis of the nature of the implementation strategies, we relied on the framework developed by Proctor et al. [41]. While most of the studies touched on five of the six dimensions included in the taxonomy adapted for this study, none directly followed the Proctor framework and thus did not readily lend themselves to being evaluated using this framework. Further, none of the studies described temporality. This is at odds with Proctor's suggestion that temporality be considered by researchers planning implementation/ intervention programs and applied systematically across study populations, unless otherwise stated, to ensure that the experimental conditions are the same. Temporality can be a critical factor contributing to the effectiveness of an implementation strategy, because peers/ CHWs' skills, knowledge, and engagement may decrease over time if not employed.

Few existing studies have employed Proctor's framework. Yet studies such as Powel et al. [59] illustrate the value of using such a standardised framework when they adopted the framework to report on a diabetes quality improvement intervention in its original commercial care setting and in community health care centres, in which actors, action, temporality, and dose were adapted to fit the local context [59]. The models of peer/CHWled program need to be further explored, especially given the inevitability of a professional healthcare workforce shortage in LMIC.

Furthermore, COMP-DSMPs have the potential to fulfil the ideals of 'triple aims of health care' defined by the Institute for Healthcare Improvement, which involves improving a patient's experiences of care, improving the health of populations, and reducing per capita costs of care. Thus, COMP-DSMPs for diabetes deserve more attention [60]. Future studies should include an assessment of cost-effectiveness due to the limited data on this aspect of COMP-DSMPs. A single study in HIC from the UK revealed no significant differences in the final cost-effectiveness endpoints for a group-based peer support intervention for type 2 diabetes in general practice [61]. Mash et al. found that a structured group education program delivered by health promotors at primary care clinics in South Africa for the management of type 2 diabetes was cost-effective [63]. Ideally, it would be important to assess cost-effectiveness in terms of traditional hard outcomes such as mortality and micro- and macrovascular complications, but the longer length of follow-up and large sample sizes are likely to be costly [62].

This systematic review has limitations. Of the 11 studies included, only 4 were RCTs and 7 were non-RCTs, including uncontrolled before and after studies. Because of the scarcity of RCTs from LMICs, these were 
included here to provide an overview of such studies previously done and to emphasise the limitations of such studies.

In conclusion, there is only limited and low level of evidence for benefit from peer support (in its broadest sense, here including $\mathrm{CHWs}$ ) in diabetes care outcomes. We recommend that future studies consider using a framework such as the MRC framework for the development and evaluation of complex interventions to inform the evidence base on the contribution of COMP-DSMP in LMIC.

\section{Supplementary information}

Supplementary information accompanies this paper at https://doi.org/10. 1186/s13643-020-01377-8.

Additional file 1. Pubmed search strategy.

Additional file 2. Cochrane risk of bias tool.

\section{Abbreviations}

LMIC: Low- and middle-income countries; CHWs: Community health workers; COMP-DSMP: Community-based peer-led diabetes self-management programs

\section{Acknowledgements}

The authors acknowledge Ms. Tamzyn Suliaman, UCT Libraries, Health Sciences and Information Services Librarian, who provided technical support and assisted in the planning of the search strategy and reference management. They gratefully acknowledge the support of the EvidenceBased Medicine Research Support Unit, Faculty of Health Sciences, at the University of Cape Town.

\section{Authors' contributions}

All authors collaborated in conceiving this study. MW and PR screened citations and full-text articles and extracted, analysed, and interpreted the data. MW wrote the initial manuscript for this study. All authors were involved in the interpretation of the data and critical revision of the manuscript. All authors read and approved the final manuscript.

\section{Funding}

Not applicable.

Ethics approval and consent to participate

Not applicable.

\section{Consent for publication}

Not applicable. Data and materials are available for reviewers upon request.

\section{Competing interests}

The authors declare that they have no competing interests.

\section{Author details}

${ }^{1}$ Chronic Disease Initiative for Africa, Cape Town, Western Cape, South Africa. ${ }^{2}$ Department of Medicine, Faculty of Health Science, University of Cape Town, Observatory, Cape Town, Western Cape 7935, South Africa. ${ }^{3}$ Chronic Diseases of Lifestyle Research Unit, Durban, Durban, South Africa. ${ }^{4}$ Department of Psychiatry, University of Oxford, Oxford, UK. ${ }^{5}$ Department of Geriatric Medicine, Faculty of Health Science, University of Cape Town, Cape Town, Western Cape, South Africa. ${ }^{6}$ South African Medical Research Council, Cape Town, South Africa. ${ }^{7}$ Division of Endocrinology and Diabetes, Chronic Diseases Initiative for Africa (CDIA), Department of Medicine, University of Cape Town, J 47 Room 86, Old Groote Schuur Hospital Building, Cape Town, South Africa.
Received: 15 January 2019 Accepted: 4 May 2020

Published online: 06 June 2020

\section{References}

1. Collaboration NRF. Worldwide trends in diabetes since 1980: a pooled analysis of 751 population-based studies with 4.4 million participants. The Lancet. 2016;387(10027):1513-30.

2. Chrvala CA, Sherr D, Lipman RD. Diabetes self-management education for adults with type 2 diabetes mellitus: a systematic review of the effect on glycemic control. Patient education and counseling. 2016;99(6):926-43.

3. Davies MJ, Heller S, Skinner T, Campbell M, Carey M, Cradock S, et al. Effectiveness of the diabetes education and self management for ongoing and newly diagnosed (DESMOND) programme for people with newly diagnosed type 2 diabetes: cluster randomised controlled trial. Bmj. 2008; 336(7642):491-5.

4. Shrivastava SR, Shrivastava PS, Ramasamy J. Role of self-care in management of diabetes mellitus. Journal of Diabetes \& Metabolic Disorders. 2013;12(1): 14.

5. Aponte J, Jackson TD, Wyka K, Ikechi C. Health effectiveness of community health workers as a diabetes self-management intervention. Diabetes and Vascular Disease Research. 2017;14(4):316-26.

6. Caro JF, Fisher EB. A solution might be within people with diabetes themselves. Family practice. 2010;27(suppl_1):i1-i2.

7. van Dam HA, Van der Horst F, Van den Borne B, Ryckman $\mathrm{R}$, Crebolder $\mathrm{H}$. Provider-patient interaction in diabetes care: effects on patient self-care and outcomes: a systematic review. Patient education and counseling. 2003; 51(1):17-28.

8. Dimatteo MR, Giordani PJ, Lepper HS, Croghan TW. Patient adherence and medical treatment outcomes a meta-analysis. Medical care. 2002:794-811.

9. Powers MA, Bardsley J, Cypress M, Duker P, Funnell MM, Fischl AH, et al. Diabetes self-management education and support in type 2 diabetes: a joint position statement of the American Diabetes Association, the American Association of Diabetes Educators, and the Academy of Nutrition and Dietetics. The Diabetes Educator. 2017;43(1):40-53.

10. Beaglehole R, Epping-Jordan J, Patel V, Chopra M, Ebrahim S, Kidd M, et al. Improving the prevention and management of chronic disease in lowincome and middle-income countries: a priority for primary health care. The Lancet. 2008;372(9642):940-9.

11. Joshi R, Alim M, Kengne AP, Jan S, Maulik PK, Peiris D, et al. Task shifting for non-communicable disease management in low and middle income countries-a systematic review. PloS one. 2014;9(8):e103754.

12. Aithal A, Jha A. Task shifting: a need for current health care system; 2017.

13. Maier $\mathrm{CB}$, Aiken $\mathrm{LH}$. Task shifting from physicians to nurses in primary care in 39 countries: a cross-country comparative study. European journal of public health. 2016;26(6):927-34.

14. Organization WH. Peer support programmes in diabetes: report of a WHO consultation, 5-7. Geneva: WHO. November 2007:2008.

15. Dennis C-L. Peer support within a health care context: a concept analysis. International journal of nursing studies. 2003;40(3):321-32.

16. Doull M, O'Connor AM, Welch V, Tugwell P, Wells GA. Peer support strategies for improving the health and well-being of individuals with chronic diseases. Cochrane Database of Systematic Reviews. 2005;3.

17. Boothroyd Rl, Fisher EB. Peers for progress: promoting peer support for health around the world. Family practice. 2010;27(suppl_1):i62-i8.

18. Lehmann U, Sanders D. Community health workers: what do we know about them. The state of the evidence on programmes, activities, costs and impact on health outcomes of using community health workers Geneva: World Health Organization. 2007:1-42.

19. Olaniran A, Smith H, Unkels R, Bar-Zeev S, van den Broek N. Who is a community health worker?-a systematic review of definitions. Global health action. 2017:10(1):1272223

20. Javanparast S, Baum F, Heidari G. Contribution of community health workers to the implementation of comprehensive primary health care in rural settings. Iran. REVITALIZING HEALTH FOR ALL. 2011;185.

21. Heisler M. Overview of peer support models to improve diabetes selfmanagement and clinical outcomes. Diabetes Spectrum. 2007;20(4):214-21.

22. Long JA. "Buddy system" of peer mentors may help control diabetes; 2012.

23. Tang TS, Funnell M, Sinco B, Piatt G, Palmisano G, Spencer MS, et al. Comparative effectiveness of peer leaders and community health workers in diabetes self-management support: results of a randomized controlled trial. Diabetes care. 2014:DC_132161. 
24. Heisler M, Vijan S, Makki F, Piette JD. Diabetes control with reciprocal peer support versus nurse care management: a randomized trial. Annals of internal medicine. 2010;153(8):507-15.

25. Funnell MM. Peer-based behavioural strategies to improve chronic disease self-management and clinical outcomes: evidence, logistics, evaluation considerations and needs for future research. Family practice. 2009; 27(suppl_1):i17-i22.

26. Norris SL, Chowdhury FM, Van Le K, Horsley T, Brownstein JN, Zhang X, et al. Effectiveness of community health workers in the care of persons with diabetes. Diabetic Medicine. 2006:23(5):544-56.

27. Babamoto KS, Sey KA, Camilleri AJ, Karlan VJ, Catalasan J, Morisky DE. Improving diabetes care and health measures among hispanics using community health workers: results from a randomized controlled trial. Health Education \& Behavior. 2009;36(1):113-26.

28. Smith SM, Paul G, Kelly A, Whitford DL, O'Shea E, O'Dowd T. Peer support for patients with type 2 diabetes: cluster randomised controlled trial. Bmj. 2011:342:d715

29. van Dam HA, van der Horst FG, Knoops L, Ryckman RM, Crebolder HF, van den Borne BH. Social support in diabetes: a systematic review of controlled intervention studies. Patient education and counseling. 2005;59(1):1-12.

30. Fisher EB, Boothroyd Rl, Elstad EA, Hays L, Henes A, Maslow GR, et al. Peer support of complex health behaviors in prevention and disease management with special reference to diabetes: systematic reviews. Clinical diabetes and endocrinology. 2017;3(1):4.

31. Baksi AK. Experiences in peer-to-peer training in diabetes mellitus: challenges and implications. Family practice. 2009;27(suppl_1):i40-i5.

32. Zhang $X$, Yang S, Sun $K$, Fisher EB, Sun X. How to achieve better effect of peer support among adults with type 2 diabetes: a meta-analysis of randomized clinical trials. Patient education and counseling. 2016;99(2):186-97.

33. Norris SL, Lau J, Smith SJ, Schmid CH, Engelgau MM. Self-management education for adults with type 2 diabetes: a meta-analysis of the effect on glycemic control. Diabetes care. 2002;25(7):1159-71.

34. Grimshaw J, Thomas R, MacLennan G, Fraser C, Ramsay C, Vale L, et al. Effectiveness and efficiency of guideline dissemination and implementation strategies. 2004.

35. Eccles M, Grimshaw J, Campbell M, Ramsay C. Research designs for studies evaluating the effectiveness of change and improvement strategies. BMJ Quality \& Safety. 2003:12(1):47-52.

36. Werfalli M, Raubenheimer $P$, Engel M, Peer N, Kalula S, Kengne AP, et al. Effectiveness of community-based peer-led diabetes self-management programmes (COMP-DSMP) for improving clinical outcomes and quality of life of adults with diabetes in primary care settings in low and middleincome countries (LMIC): a systematic review and meta-analysis. BMJ open. 2015;5(7):e007635.

37. Sterne JA, Hernán MA, Reeves BC, et al. ROBINS-l: a tool for assessing risk of bias in non-randomised studies of interventions. BMJ. 2016;355:14919.

38. Hutton B, Salanti G, Caldwell DM, Chaimani A, Schmid CH, Cameron C, et al. The PRISMA extension statement for reporting of systematic reviews incorporating network meta-analyses of health care interventions: checklist and explanations. Annals of internal medicine. 2015;162(11):777-84.

39. Bank W. Country classification. World Bank Washington^ eDC DC; 2010.

40. Higgins JP, Altman DG, Gøtzsche PC, Jüni P, Moher D, Oxman AD, et al. The Cochrane Collaboration's tool for assessing risk of bias in randomised trials. Bmj. 2011;343:d5928.

41. Proctor EK, Powell BJ, McMillen JC. Implementation strategies: recommendations for specifying and reporting. Implementation Science. 2013;8(1):139.

42. Proctor $E$, Silmere $H$, Raghavan $R$, Hovmand $P$, Aarons $G$, Bunger $A$, et al. Outcomes for implementation research: conceptual distinctions, measurement challenges, and research agenda. Administration and Policy in Mental Health and Mental Health Services Research. 2011;38(2):65-76.

43. Assah F, Atanga E, Enoru S, Sobngwi E, Mbanya J. Community-based peer support significantly improves metabolic control in people with type 2 diabetes in Yaoundé. Cameroon. Diabetic Medicine. 2015;32(7):886-9.

44. Baumann LC, Frederick N, Betty N, Jospehine E, Agatha N. A demonstration of peer support for ugandan adults with type 2 diabetes. International journal of behavioral medicine. 2015;22(3):374-83.

45. Eggermont N. Evaluation of a peer-education program for diabetes and hypertension in rural Cambodia. Ghent: University of Ghent; 2011.

46. Rotheram-Borus MJ, Tomlinson M, Gwegwe M, Comulada WS, Kaufman N, Keim M. Diabetes buddies: peer support through a mobile phone buddy system. The Diabetes Educator. 2012;38(3):357-65.
47. Shen $\mathrm{H}$. Effectiveness of a peer-led self-management program for older people with type 2 diabetes in China: Queensland University of Technology; 2008.

48. Less LA, Ragoobirsingh D, Morrison EY, Boyne M, Johnson PA. A preliminary report on an assessment of a community-based intervention for diabetes control in adults with type 2 diabetes. Family practice. 2009;27(suppl_1):i46-i52.

49. Micikas M, Foster J, Weis A, Lopez-Salm A, Lungelow D, Mendez P, et al. A community health worker intervention for diabetes self-management among the Tz'utujil Maya of Guatemala. Health promotion practice. 2015; 16(4):601-8.

50. Debussche X, BesancËon S, Balcou- Debussche M, Ferdynus C, Delisle H, Huiart $L$, et al. (2018) Structured peer-led diabetes self-management and support in a low-income country: the ST2EP randomised controlled trial in Mali. PLOS ONE 13(1): e0191262. https://doi.org/10.1371/journal.pone.0191262.

51. Zhong X, Wang Z, Fisher EB, Tanasugarn C. Peer support for diabetes management in primary care and community settings in Anhui Province. China. The Annals of Family Medicine. 2015;13(Suppl 1):S50-S8.

52. Gagliardino JJ, Arrechea V, Assad D, Gagliardino GG, González L, Lucero S, et al. Type 2 diabetes patients educated by other patients perform at least as well as patients trained by professionals. Diabetes/metabolism research and reviews. 2013;29(2):152-60.

53. Mash R, Rhode H, Zwarenstein M, Rollnick S, Lombard C, Steyn K, et al. Effectiveness of a group diabetes education programme in under-served communities in South Africa: a pragmatic cluster randomized controlled trial. Diabetic Medicine. 2014;31(8):987-93.

54. Carroll C, Patterson M, Wood S, Booth A, Rick J, Balain S. A conceptual framework for implementation fidelity. Implementation science. 2007;2(1):40

55. Webel AR, Okonsky J, Trompeta J, Holzemer WL. A systematic review of the effectiveness of peer-based interventions on health-related behaviors in adults. American journal of public health. 2010;100(2):247-53.

56. Dale J, Williams S, Bowyer V. What is the effect of peer support on diabetes outcomes in adults? A systematic review. Diabetic Medicine. 2012;29(11):1361-77.

57. Simmons D, Prevost AT, Bunn C, Holman D, Parker RA, Cohn S, et al. Impact of community based peer support in type 2 diabetes: a cluster randomised controlled trial of individual and/or group approaches. PLoS One. 2015; 10(3):e0120277.

58. Small N, Blickem C, Blakeman T, Panagioti M, Chew-Graham CA, Bower P. Telephone based self-management support by 'lay health workers' and 'peer support workers' to prevent and manage vascular diseases: a systematic review and meta-analysis. BMC health services research. 2013; 13(1):533.

59. Powell BJ, Beidas RS, Lewis CC, Aarons GA, McMillen JC, Proctor EK, et al. Methods to improve the selection and tailoring of implementation strategies. J Behav Health Serv Res. 2017;44(2):177-94.

60. Katon WJ, Unützer J. Health reform and the Affordable Care Act: the importance of mental health treatment to achieving the triple aim. Journal of Psychosomatic Research. 2013;74(6):533-7.

61. Gillespie P, O'Shea E, Paul G, O'Dowd T, Smith SM. Cost effectiveness of peer support for type 2 diabetes. International journal of technology assessment in health care. 2012;28(1):3-11.

62. Mash R, Kroukamp R, Gaziano T, Levitt N. Cost-effectiveness of a diabetes group education program delivered by health promoters with a guiding style in underserved communities in Cape Town, South Africa. Patient education and counseling. 2015;98(5):622-6.

\section{Publisher's Note}

Springer Nature remains neutral with regard to jurisdictional claims in published maps and institutional affiliations.

\section{Ready to submit your research? Choose BMC and benefit from:}

- fast, convenient online submission

- thorough peer review by experienced researchers in your field

- rapid publication on acceptance

- support for research data, including large and complex data types

- gold Open Access which fosters wider collaboration and increased citations

- maximum visibility for your research: over $100 \mathrm{M}$ website views per year

At $\mathrm{BMC}$, research is always in progress.

Learn more biomedcentral.com/submissions 